\title{
Influência do Desempenho Térmico de Moldes Fabricados com Compósito Epóxi/Alumínio nas Propriedades de PP Moldado por Injeção
}

\author{
Gean V. Salmoria, Carlos H. Ahrens, Felix A. Y. Villamizar, Aurélio da C. Sabino Netto \\ Departamento de Engenharia Mecânica, UFSC
}

\begin{abstract}
Resumo: O surgimento das tecnologias de prototipagem rápida (RP) e de ferramental rápido (RT) tem despertado interesse da indústria de moldes de injeção. O vazamento de termofixos com cargas metálicas possibilita a construção de moldes usando materiais compósitos, os quais apresentam maior resistência que os utilizados por outras técnicas RT. Neste trabalho foi estudado o comportamento térmico de moldes fabricados em epóxi/alumínio durante a injeção de polipropileno através de avaliações da estrutura e de propriedades mecânicas utilizando difração de raio X e ensaios de dureza e de tração. Os corpos-de-prova injetados no molde em compósito epóxi/alumínio apresentaram pequenas diferenças no grau de cristalinidade das superfícies analisadas e propriedades mecânicas semelhantes aos corpos-de-prova injetados em molde de aço. $\mathrm{O}$ estudo mostrou um razoável desempenho térmico do molde compósito durante a injeção de polipropileno evidenciando a viabilidade de utilização destes moldes na produção de pequenas séries de protótipos e de produtos neste termoplástico.
\end{abstract}

Palavras-chave: Desempenho térmico, molde compósito, moldagem por injeção de polipropileno.

\section{Thermal Behavior of Epoxy/Aluminum Rapid Tooling Composite During Injection Molding of Polypropylene}

\begin{abstract}
RP) and rapid tooling (RT) technologies are gaining increasing importance in the injection molding industry. Casting of resin/metal composites allows the construction of molds with greater resistance than those manufactured by other RT techniques such as Stereolithography. In this work, the thermal behavior of molds manufactured in epoxy/aluminum during the injection molding of polypropylene specimens was investigated. Structural and mechanical characterization of the molded specimens included X ray analysis, hardness and tensile testing. The samples presented small differences in the degree of crystallinity and similar mechanical properties in comparison with samples injected into steel molds. This study showed a reasonable thermal performance of the epoxy/aluminum mold during the injection molding of polypropylene, thus demonstrating the viability of using these molds to produce a few number of prototypes or products with this thermoplastic.
\end{abstract}

Keywords: Thermal behavior, composite mold, polypropylene injection molding.

\section{Introdução}

No desenvolvimento de produtos poliméricos injetados a etapa de fabricação do molde é uma das mais críticas devido ao alto custo e longo tempo de fabricação. O surgimento das tecnologias de prototipagem rápida (RP-Rapid Prototyping) e de ferramental rápido (RT-Rapid Tooling) favoreceu o processo de desenvolvimento de produtos em tempos menores com boa precisão dimensional, fomentando o crescimento da competitividade das empresas e a introdução no mercado de idéias inovadoras de uma forma rápida e eficaz ${ }^{[1-7]}$. Entre as tecnologias de ferramental rápido que têm recebido destaque, encontra-se o vazamento de resina com cargas metálicas. Esta técnica possibilita a construção de moldes usando materiais compósitos de maior resistência que os utilizados por outras técnicas $\mathrm{RT}^{[8-10]}$. Contudo, o desempenho térmico destes materiais durante a moldagem por injeção vem sendo pouco investigado ${ }^{[11]}$.
Durante a etapa de projeto de um molde para injeção de termoplásticos é desejável que se obtenha recomendações visando assegurar uma troca de calor eficiente, garantindo assim um resfriamento uniforme na peça. No ciclo de moldagem por injeção, o resfriamento inicia-se simultaneamente com a injeção do termoplástico na cavidade. O material é resfriado desde o instante em que tem contato com as paredes da cavidade, as quais se encontram a uma temperatura menor. A etapa de resfriamento se estende além da etapa de recalque, até o momento em que a peça está suficientemente fria para ser extraída, normalmente abaixo da temperatura de amolecimento do termoplástico. A transferência de calor ocorre principalmente por condução, entre o termoplástico injetado e o molde, entre o molde e o fluido contido nos canais de resfriamento, e por convecção forçada do fluido de resfriamento ao percorrer os canais de resfriamento. Trata-se, portanto, de um fenômeno cuja previsão é relativamente complexa.

Autor para correspondência: Carlos H. Ahrens, Laboratório CIMJECT, Departamento de Engenharia Mecânica, UFSC, CEP: 88040-900, Florianópolis, SC, Brasil.E-mail: chahrens@cimject.ufsc.br 
Buscando compreender tal fenômeno, Li et al. ${ }^{[12]}$ propuseram descrever o balanço de energia em um molde de injeção com base nas Equações 1, 2 e $3^{[12]}$ :

$$
\begin{aligned}
& Q_{\text {plast }}=\left[\left(T_{M}-T_{E}\right) \cdot C_{p}+i_{m}\right] \cdot \rho_{M} \cdot \frac{S}{2} \cdot x\left[\mathrm{~J} \cdot \mathrm{m}^{-1}\right] \\
& Q_{W}=t_{k} \cdot\left(\frac{1}{\alpha \cdot \rho_{\text {mould }} \cdot C_{p} \cdot S_{e}}+\frac{1}{h \cdot \pi \cdot D}\right)^{-1} \cdot \\
& \left(T_{W}-T_{\text {fluido }}\right)\left[\mathrm{J} \cdot \mathrm{m}^{-1}\right] \\
& Q_{\text {Plast }}=Q_{w}
\end{aligned}
$$

sendo $\mathrm{Q}_{\text {plast }}$ a quantidade de calor fornecido pelo termoplástico para o molde; $\mathrm{Q}_{\mathrm{w}}$ o calor transferido do molde para $\mathrm{o}$ fluido de resfriamento através das paredes da cavidade; $\mathrm{S}_{\mathrm{e}} \mathrm{o}$ fator de forma (obtido por $S_{e}=2 \pi / \operatorname{Ln}(2 x \cdot \operatorname{Sinh}(2 \pi y) / \pi D) ; S$ a espessura da peça; $x$, a distância entre os canais de resfriamento; $\mathrm{D}$ o diâmetro do canal de resfriamento; $\mathrm{t}_{\mathrm{k}}$ o tempo de resfriamento; $\alpha$, a difusividade térmica do material do molde; $\rho_{\text {mould }}$ a densidade do material do molde; $\mathrm{C}_{\mathrm{p} \text { mould }}$ o calor específico do material do molde; $\mathrm{T}_{\mathrm{M}}$ a temperatura do termoplástico injetado na cavidade; $\mathrm{T}_{\mathrm{E}}$ a temperatura na qual a peça injetada é extraída do molde; $\mathrm{T}_{\text {fluido }}$ a temperatura do fluido de resfriamento; $\mathrm{T}_{\mathrm{w}}$ a temperatura da parede da cavidade do molde; $\mathrm{C}_{\mathrm{p}}$ o calor específico do termoplástico; $\mathrm{I}_{\mathrm{M}}$ a entalpia de fusão do termoplástico; $\rho_{\mathrm{M}}$ a densidade do termoplástico; e h o coeficiente de transferência de calor por convecção (para água $h=0,0314 / \mathrm{D} \cdot \mathrm{Re} \cdot 0.8$; sendo Re, o número do Reynolds).

Desta maneira, a taxa de transferência de calor do termoplástico para o molde $\left(\mathrm{Q}_{\text {plast }} / \mathrm{t}_{\mathrm{k}}\right)$ foi descrita como sendo função das propriedades térmicas do termoplástico, do molde e das condições do fluido de resfriamento. Portanto, as equações evidenciam que as moldagens de um mesmo polímero sob mesmas condições de fluido de resfriamento em moldes não-metálicos (como os fabricados por tecnologia RT em compósito epóxi/alumínio) proporcionam uma mais lenta transferência de calor da peça para o molde e do molde para o fluido de resfriamento, se comparadas às moldagens realizadas em moldes metálicos convencionais. Esta lenta transferência de calor se deve à baixa difusividade térmica $(\alpha)$ destes moldes. Tal justificativa pode ser explicada ao se considerar a Equação 4:

$$
\alpha=\frac{\lambda}{\rho \cdot C_{p}}\left[\mathrm{~m}^{2} / \mathrm{s}\right]
$$

sendo $\lambda$ a condutividade térmica; $\mathrm{C}_{\mathrm{p}}$ o calor específico; e $\rho$ a densidade do material. Nela, fica evidenciado que a baixa difusividade térmica $(\alpha)$ do material do molde fabricado em compósito epóxi/alumínio decorre dos baixos valores de condutividade térmica, que para a maioria dos materiais poliméricos encontra-se na faixa de $0,1-0,4 \mathrm{~W} / \mathrm{m} \cdot \mathrm{K}$, e baixos valores de calor específico, na faixa de $0,3-2,3 \mathrm{KJ} / \mathrm{Kg} \cdot \mathrm{K}^{[13,14]}$.
Para fins de fabricação de componentes injetados, é importante investigar se a baixa difusividade térmica do molde não-metálico não compromete o desempenho das peças injetadas, gerando alterações significativas de estrutura e de propriedades.

Este trabalho investiga a influência do desempenho térmico de um molde em compósito epóxi/alumínio, nas propriedades de peças injetadas em polipropileno, por meio de análises da estrutura superficial e de propriedades mecânicas utilizando-se de técnicas de difração de raio $\mathrm{X}$, ensaios de dureza e resistência à tração.

\section{Experimental}

\section{Projeto e fabricação do molde e procedimento de injeção}

Para a realização dos experimentos foi projetado um molde $(130 \times 75 \times 70 \mathrm{~mm})$ de um corpo-de-prova para ensaio de resistência à tração (norma ASTM D-638 tipo IV). Visando encontrar um resfriamento homogêneo, eficaz e uma solução de fácil fabricação o sistema de resfriamento do molde foi projetado com variadas alternativas de configuração. A escolha da configuração a ser fabricada foi realizada baseando-se em resultados de simulações do processo de injeção no software Moldflow Insight 5.1 e considerando a facilidade de fabricação por conformação de tubos de cobre. Tubos de cobre com diâmetro interno de $4,5 \mathrm{~mm}$ foram escolhidos para a construção do sistema de canais em série, uma vez que tubos com diâmetros maiores apresentariam limitações dimensionais.

As simulações mostraram que com o posicionamento dos canais a $3 \mathrm{~mm}$ da superfície e entrada do fluido de resfriamento pelo lado oposto ao ponto de injeção, os tempos de resfriamento (até a solidificação do material) seriam similares ao longo da parte central da peça, o que sugere um resfriamento quase uniforme nesta região (Figura 1). Regiões que apresentaram um tempo menor de resfriamento foram observadas próximas do ponto de injeção e na região mais distante ao ponto de injeção onde se estabeleceu a entrada do fluido no sistema de resfriamento.

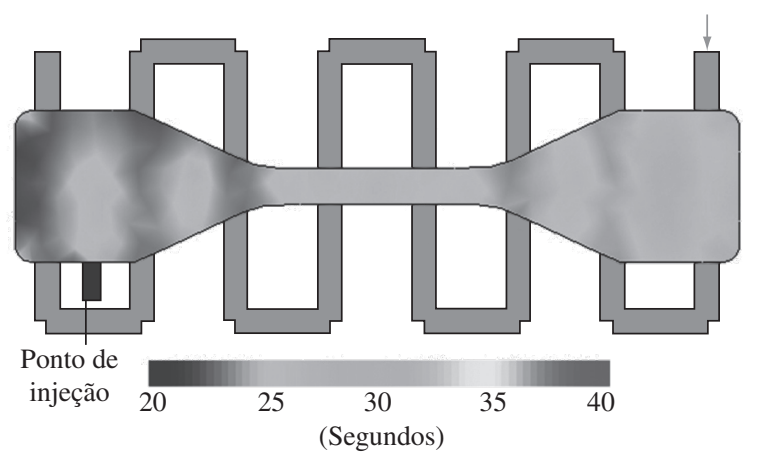

Figura 1. Simulação do tempo de resfriamento usando Moldflow, para uma peça em PP injetada em um molde epóxi/alumínio com o canal de resfriamento colocado a $3 \mathrm{~mm}$ da superfície circulando fluido de resfriamento a $15{ }^{\circ} \mathrm{C}$. 
Tabela 1. Parâmetros de injeção usados na injeção de PP nos moldes em compósito epóxi/alumínio e aço AISI 1045.

\begin{tabular}{cc}
\hline & Valor \\
\hline Pressão de injeção $(\mathrm{MPa})$ & 20 \\
Pressão de recalque $(\mathrm{MPa})$ & 17 \\
Temperatura do molde $\left({ }^{\circ} \mathrm{C}\right)$ & $15,32,75$ \\
Temperaturas de zonas de & $205-200-195$ \\
aquecimento $\left({ }^{\circ} \mathrm{C}\right)$ & $190-185$ \\
\hline
\end{tabular}

Uma vez definida a configuração do sistema de resfriamento foi fabricado um molde pela técnica de vazamento, usando o compósito epóxi/alumínio RenCast 436, o endurecedor Ren 1500 e o desmoldante Z50, fornecidos pela HUNSTMAN. Para o monitoramento da temperatura no molde em compósito, foram instalados dois termopares tipo $\mathrm{K}$ a $2 \mathrm{~mm}$ da superfície, no centro da cavidade e no ponto de injeção.

Foi fabricado um corpo-de-prova por estereolitografia para ser usado como modelo na fabricação da cavidade pela técnica de vazamento. Os pinos extratores foram posicionados antes de realizar o vazamento do compósito epóxi/alumínio na moldura, para evitar processos de furação.

$\mathrm{Na}$ moldagem por injeção foi utilizada a máquina injetora Arburg 320S 500-150 cujos parâmetros de processo (Tabela 1) foram estabelecidos baseando-se nos resultados das simulações, e seguindo o procedimento de injeção progressiva. Peças em polipropileno isotático (PP) PH 3515, fornecido pela Ipiranga, foram injetadas no molde em compósito epóxi/alumínio, e em um molde de aço de mesma geometria. A água foi utilizada a três temperaturas diferentes, 15,32 e $75{ }^{\circ} \mathrm{C}$ como fluido de resfriamento. Para cada temperatura do fluido de resfriamento, foi injetado um total de 15 corpos-de-prova em cada molde, visando posteriormente avaliar a estrutura e as propriedades das peças em PP, e indiretamente o desempenho térmico do molde em compósito epóxi/alumínio comparado com o molde em aço.

\section{Ensaios de dureza}

Um total de 10 corpos-de-prova para cada condição de temperatura do fluido de resfriamento do molde foi utilizado para a determinação da dureza Shore D. Para este ensaio foi utilizado o durômetro WULTEST SD 300 com resolução de um digito. A dureza foi medida em 11 pontos distribuídos ao longo da peça (Figura 2) para registrar qualquer possí-

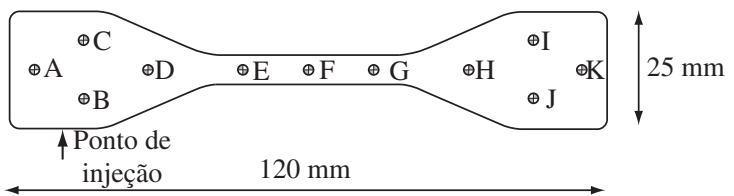

Figura 2. Representação dos pontos de medição de dureza nos corpos-deprova. vel variação desta grandeza por efeitos de um resfriamento não-uniforme.

\section{Ensaios de resistência à tração}

Para determinação de propriedades mecânicas como resistência à tração (tensão máxima) e módulo de elasticidade das peças injetadas, foram realizados ensaios em uma máquina universal EMIC, de acordo com a norma ASTM D-638. Para os ensaios a cada condição de temperatura do fluido de resfriamento do molde foram utilizadas 5 amostras. A velocidade de deformação durante o ensaio foi de $5 \mathrm{~mm} / \mathrm{min}$, com célula de carga de $500 \mathrm{~N}$ e a temperatura dos ensaios foi de $20{ }^{\circ} \mathrm{C}$. A deformação foi medida com um extensômetro longitudinal de $50 \mathrm{~mm}$ de base de medida.

\section{Difração de raio $X$}

Um difratômetro de raio X Philips modelo X'PERT MPD com radiação $\mathrm{K} \alpha$ do Cobre foi utilizado nas análises de difração de raio $\mathrm{X}$ da superfície das diferentes amostras. Para a análise dos difratogramas por deconvolução e determinação do grau de cristalinidade por DRX, foi usado o software Origin Pro 7.5.

$\mathrm{O}$ grau de cristalinidade $\mathrm{X}_{\mathrm{c}}$ foi determinado por DRX em função das áreas correspondentes aos picos cristalinos e da área do halo amorfo (pico alargado sob os picos cristalinos):

$$
X_{c}=A_{c} /\left(A_{\mathrm{c}}+A_{\mathrm{a}}\right)
$$

onde $A_{c}$ representa a soma das áreas dos picos cristalinos e $\mathrm{A}_{\mathrm{a}}$ corresponde à área do halo amorfo. $\mathrm{O}$ fator $\mathrm{K}$ de Turner-Jones determina a fração de fase $\beta$. a partir das áreas dos picos correspondentes às fases $\alpha$ e $\beta$ do polipropileno $^{[15,16]}$.

$$
K=A_{300 \beta} /\left(A_{300 \beta}+A_{110 \alpha}+A_{040 \alpha}+A_{130 \alpha}\right)
$$

As percentagens de fase $\beta$ e de fase $\alpha$ são dadas pelas Equações 7 e 8:

$$
\begin{aligned}
& \beta=K \times X_{c} \\
& \alpha=X_{c}-K \times X_{c}
\end{aligned}
$$

\section{Resultados e Discussão}

\section{Processo de injeção e caracterização das peças injetadas}

O controle da temperatura em moldes poliméricos é importante para evitar a falha prematura destes, motivada por aquecimentos excessivos durante a injeção. No procedimento de injeção dos corpos-de-prova de PP no molde de epóxi/alumínio e no molde de aço em diferentes temperatu- 
ras do fluido de resfriamento, os ciclos de injeção foram de 200 segundos, buscando o resfriamento do molde com ciclos não muito longos. A Figura 3 ilustra os valores de temperatura registrados no período de 2000 a 3000 segundos quando o processo entrou em regime estável. A temperatura

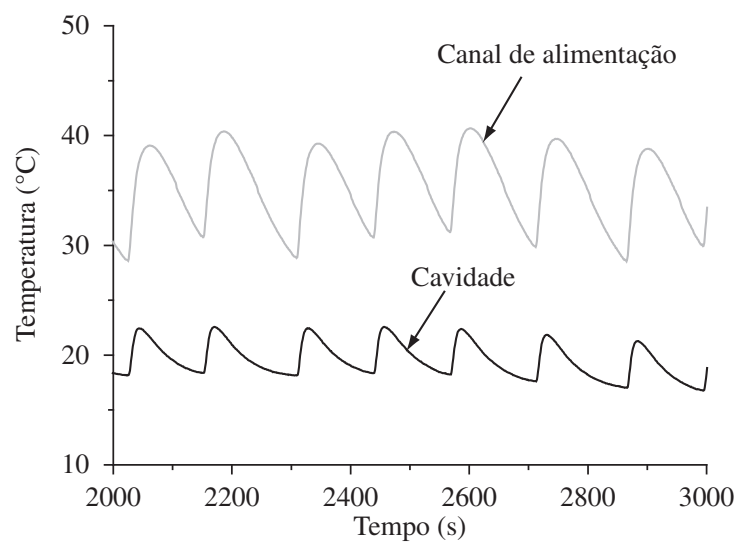

(a)

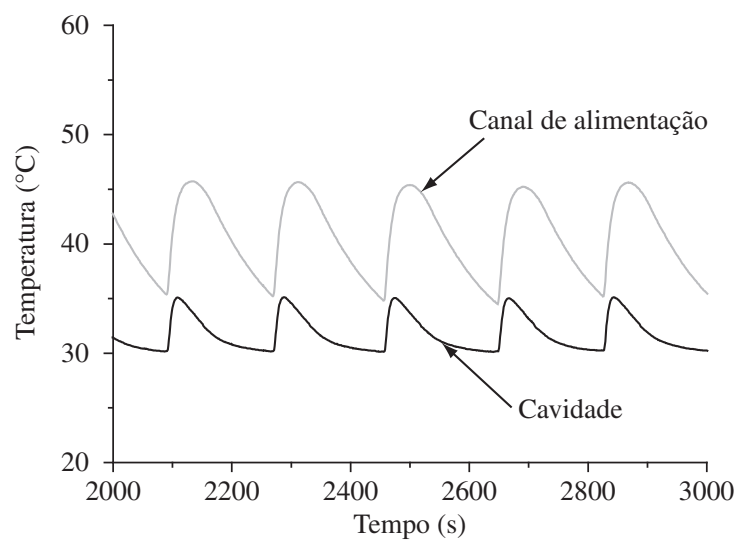

(b)

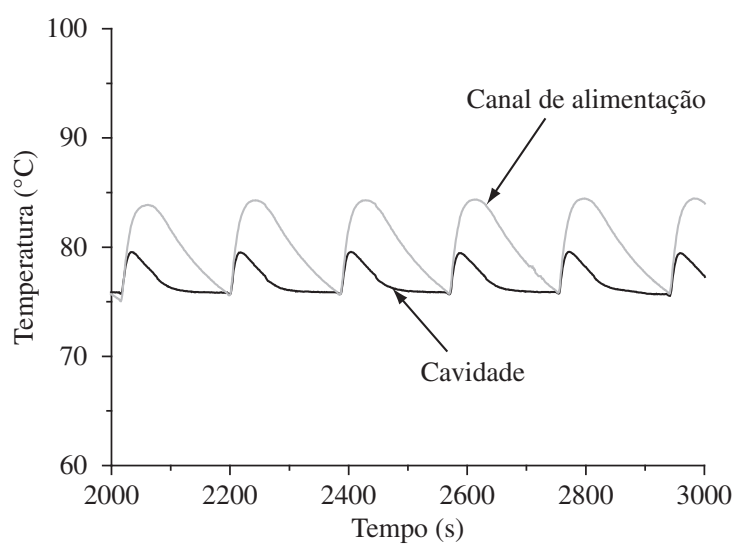

(c)

Figura 3. Temperatura do molde em compósito epóxi/alumínio durante a injeção de PP usando fluido de resfriamento a) $15^{\circ} \mathrm{C}$; b) $32{ }^{\circ} \mathrm{C}$; e c) $75^{\circ} \mathrm{C}$. no canal de alimentação atingiu valores acima dos registrados na cavidade, e consequentemente tempos de resfriamento ligeiramente maiores que os indicados nos resultados da simulação, evidenciando eventuais limitações do software de CAE para simulações de moldagem em moldes não-metálicos.

Os valores de dureza média nos diferentes pontos dos corpos-de-prova injetados no molde em compósito epóxi/alumínio, em função da temperatura do fluido de resfriamento, são apresentados na Tabela 2. Ao comparar a dureza entre os diferentes pontos do corpo-de-prova a uma mesma temperatura, observou-se uma variação insignificante que pode estar ligada a diferenças localizadas na morfologia e/ou diferenças dimensionais causadas por contração diferenciada

Tabela 2. Dureza média Shore D e desvio padrão em pontos nos corpos de prova de PP (Figura 2) injetados no molde em compósito epóxi/alumínio e no molde em aço para diferentes temperaturas do fluido de resfriamento.

\begin{tabular}{|c|c|c|c|c|c|c|}
\hline \multirow{3}{*}{$\begin{array}{c}\text { Pontos molde } \\
\text { compósito }\end{array}$} & \multicolumn{6}{|c|}{$\begin{array}{l}\text { Temperatura do fluido de } \\
\text { resfriamento }\left({ }^{\circ} \mathbf{C}\right)\end{array}$} \\
\hline & \multicolumn{2}{|c|}{15} & \multicolumn{2}{|c|}{32} & \multicolumn{2}{|c|}{75} \\
\hline & 74,3 & $\pm 0,8$ & 73,5 & $\pm 0,5$ & 74,5 & $\pm 1,8$ \\
\hline $\mathrm{B}$ & 72,6 & $\pm 0,8$ & 71,5 & $\pm 1,1$ & 73,2 & $\pm 2,0$ \\
\hline $\mathrm{C}$ & 72,0 & $\pm 0,9$ & 71,4 & $\pm 1,5$ & 73,9 & $\pm 1,0$ \\
\hline $\mathrm{D}$ & 70,4 & $\pm 0,7$ & 71,0 & $\pm 0,7$ & 70,9 & $\pm 1,4$ \\
\hline $\mathrm{E}$ & 72,5 & $\pm 0,8$ & 72,0 & $\pm 0,5$ & 71,9 & $\pm 0,6$ \\
\hline $\mathrm{F}$ & 71,8 & $\pm 0,6$ & 71,4 & $\pm 0,8$ & 72,0 & $\pm 0,5$ \\
\hline $\mathrm{G}$ & 71,7 & $\pm 0,9$ & 71,1 & $\pm 0,9$ & 72,2 & $\pm 0,8$ \\
\hline $\mathrm{H}$ & 68,6 & $\pm 1,1$ & 69,4 & $\pm 1,0$ & 70,1 & $\pm 1,0$ \\
\hline I & 69,6 & $\pm 1,3$ & 71,3 & $\pm 1,3$ & 71,6 & $\pm 2,4$ \\
\hline $\mathrm{J}$ & 70,6 & $\pm 1,2$ & 70,5 & $\pm 1,8$ & 72,3 & $\pm 1,9$ \\
\hline $\mathrm{K}$ & 73,9 & $\pm 0,6$ & 74,4 & $\pm 0,7$ & 74,4 & $\pm 1,6$ \\
\hline Média geral & 71,6 & $\pm 0,9$ & 71,6 & $\pm 1,0$ & 72,4 & $\pm 1,4$ \\
\hline \multirow[t]{2}{*}{$\begin{array}{l}\text { Pontos } \\
\text { molde aço }\end{array}$} & \multicolumn{6}{|c|}{$\begin{array}{l}\text { Temperatura do fluido de } \\
\text { resfriamento }\left({ }^{\circ} \mathbf{C}\right)\end{array}$} \\
\hline & \multicolumn{2}{|c|}{15} & \multicolumn{2}{|c|}{32} & \multicolumn{2}{|c|}{75} \\
\hline A & 72,6 & $\pm 1,1$ & 72,7 & $\pm 0,5$ & 74,6 & $\pm 0,5$ \\
\hline B & 70,2 & $\pm 0,6$ & 69,6 & $\pm 1,1$ & 73,2 & $\pm 0,9$ \\
\hline $\mathrm{C}$ & 72,1 & $\pm 0,7$ & 72,3 & $\pm 0,7$ & 74,7 & $\pm 0,5$ \\
\hline $\mathrm{D}$ & 69,9 & $\pm 0,7$ & 70,0 & $\pm 0,7$ & 72,8 & $\pm 0,8$ \\
\hline $\mathrm{E}$ & 72,3 & $\pm 0,9$ & 71,9 & $\pm 0,6$ & 73,9 & $\pm 0,3$ \\
\hline $\mathrm{F}$ & 71,7 & $\pm 0,8$ & 71,6 & $\pm 0,5$ & 73,6 & $\pm 0,5$ \\
\hline $\mathrm{G}$ & 71,9 & $\pm 0,6$ & 71,6 & $\pm 0,7$ & 73,9 & $\pm 0,7$ \\
\hline $\mathrm{H}$ & 70,0 & $\pm 0,5$ & 69,7 & $\pm 0,7$ & 72,6 & $\pm 0,7$ \\
\hline I & 70,8 & $\pm 0,6$ & 70,9 & $\pm 0,6$ & 73,7 & $\pm 0,7$ \\
\hline $\mathrm{J}$ & 71,2 & $\pm 0,8$ & 71,0 & $\pm 0,7$ & 73,5 & $\pm 0,8$ \\
\hline $\mathrm{K}$ & 71,2 & $\pm 1,0$ & 70,9 & $\pm 0,6$ & 73,7 & $\pm 0,7$ \\
\hline Média geral & 71,3 & $\pm 0,7$ & 71,1 & $\pm 0,7$ & 73,6 & $\pm 0,6$ \\
\hline
\end{tabular}


(rechupes), principalmente nas regiões próximas aos pontos D e H (Figura 2). O mesmo comportamento foi observado para as peças injetadas no molde de aço, porém em menor intensidade.

A dureza das peças injetadas no molde epóxi/alumínio e no molde em aço com o fluido de resfriamento na temperatura de $75^{\circ} \mathrm{C}$ foram ligeiramente superiores à dureza das peças injetadas com o fluido de resfriamento na temperatura de 15 e $32{ }^{\circ} \mathrm{C}$ (Tabela 2 ). O valor de dureza média geral dos corpos-de-prova injetados no molde de aço a $75^{\circ} \mathrm{C}$ (73,6 shore D) foi ligeiramente superior ao obtido nas peças injetadas em molde epóxi/alumínio (72,4 shore D).

As curvas de tensão em função da deformação dos corpos-de-prova em PP injetados nos moldes em compósito epóxi/alumínio e em aço são mostradas na Figura 4. O comportamento em tração para todos os corpos-de-prova de PP foi semelhante, apresentando um comportamento inicialmente elástico até tensões na ordem de $22 \mathrm{MPa}$. A partir de

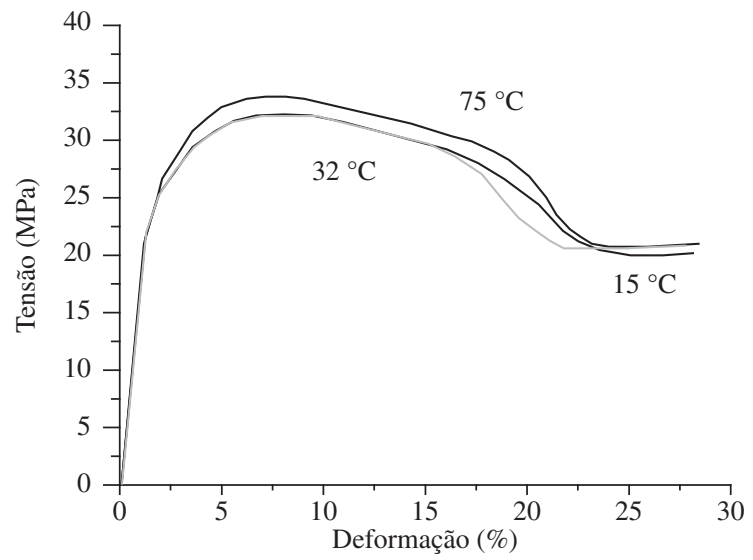

(a)

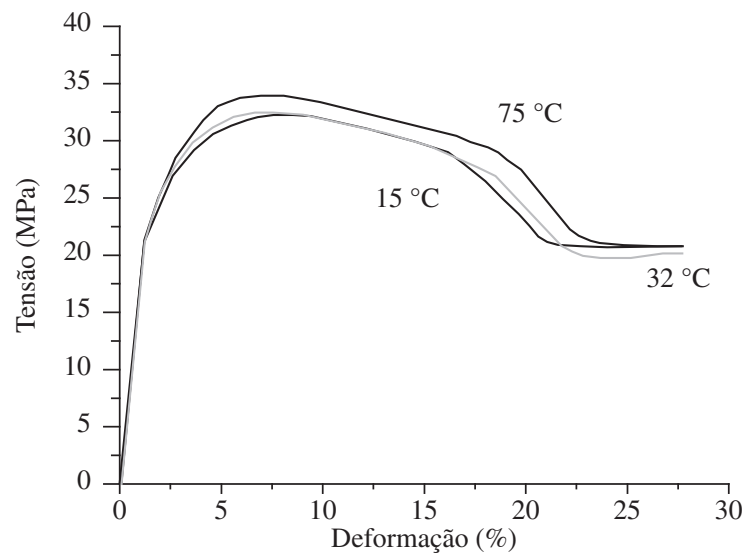

(b)

Figura 4. Tensão vs. deformação para corpos-de-prova de PP injetados em molde de compósito epóxi/alumínio: a) em molde aço; e b) com fluido de resfriamento a 15,32 e $75{ }^{\circ} \mathrm{C}$. tensões mais elevadas os corpos-de-prova apresentaram comportamento não-linear característico de deformações elásticas e plásticas e, posteriormente, comportamento plástico. Os ensaios foram conduzidos somente até deformações na ordem de $30 \%$, devido a limitações dimensionais do extensômetro usado.

Tabela 3. Tensão de escoamento e módulo de elasticidade dos corpos de prova em PP injetados em moldes de compósito epóxi/alumínio e de aço AISI 1045.

\begin{tabular}{cccc}
\hline $\begin{array}{c}\text { Temperatura do } \\
\text { fluido de } \\
\text { resfriamento }\left({ }^{\circ} \mathbf{C}\right)\end{array}$ & $\begin{array}{c}\text { Material do } \\
\text { molde }\end{array}$ & $\begin{array}{c}\text { Módulo de } \\
\text { elasticidade } \\
(\mathbf{M P a})\end{array}$ & $\begin{array}{c}\text { Tensão de } \\
\text { escoamento } \\
(\mathbf{M P a})\end{array}$ \\
\hline 15 & Aço & $1810 \pm 50$ & $32 \pm 1$ \\
& Epóxi/al & $1822 \pm 40$ & $32 \pm 1$ \\
32 & Aço & $1836 \pm 60$ & $32 \pm 2$ \\
& Epóxi/al & $1828 \pm 50$ & $32 \pm 1$ \\
75 & Aço & $1830 \pm 40$ & $34 \pm 1$ \\
& Epóxi/al & $1833 \pm 50$ & $34 \pm 1$ \\
\hline
\end{tabular}

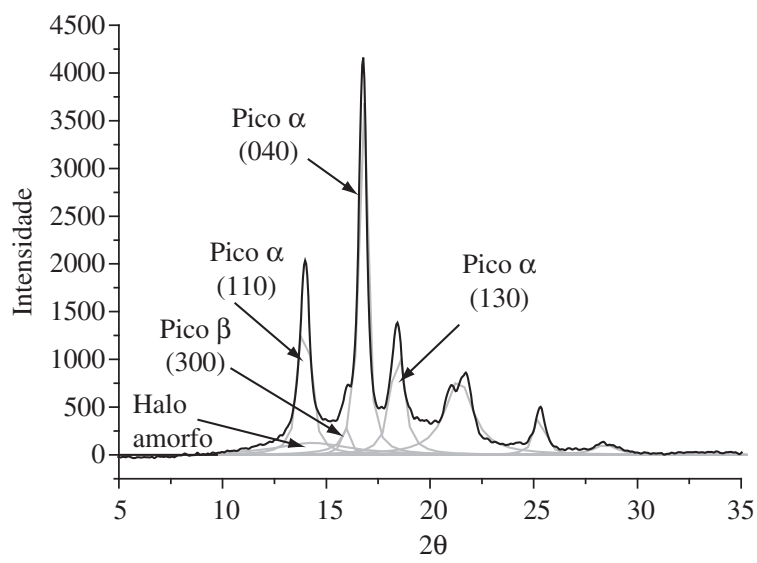

(a)

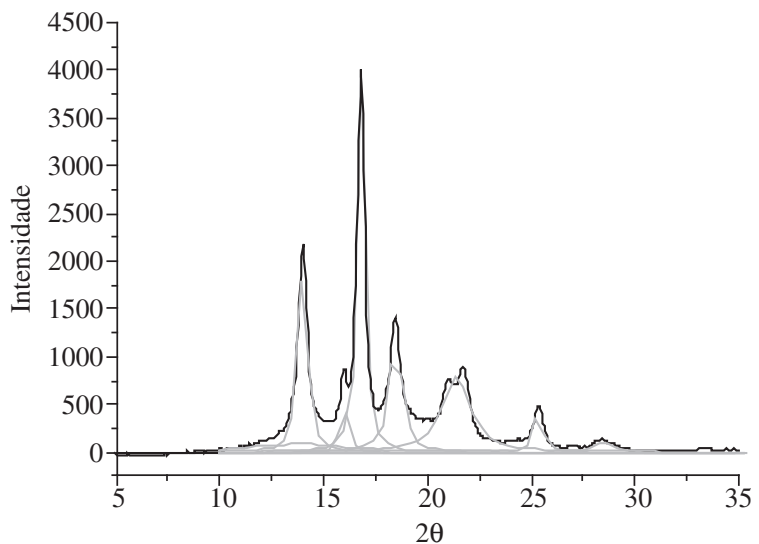

(b)

Figura 5. Difratograma da superfície de amostra de PP injetada no molde em compósito epóxi/alumínio com fluido de resfriamento a) $15{ }^{\circ} \mathrm{C}$; e b) $75^{\circ} \mathrm{C}$. 


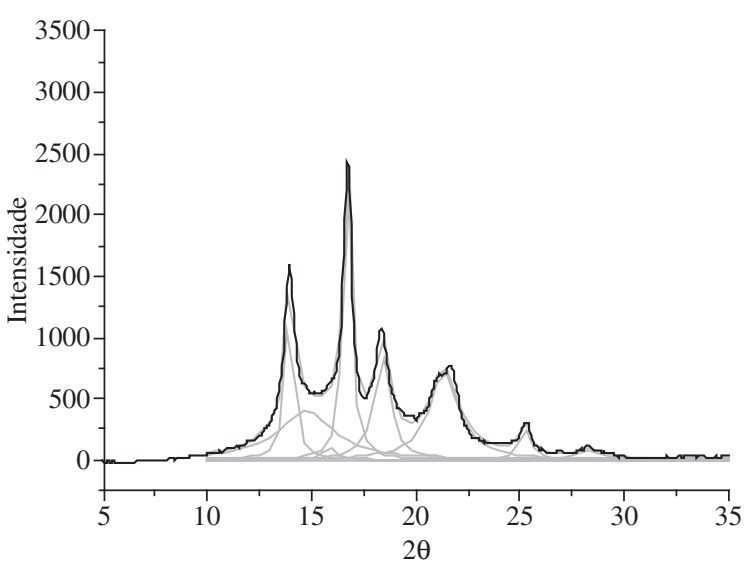

(a)

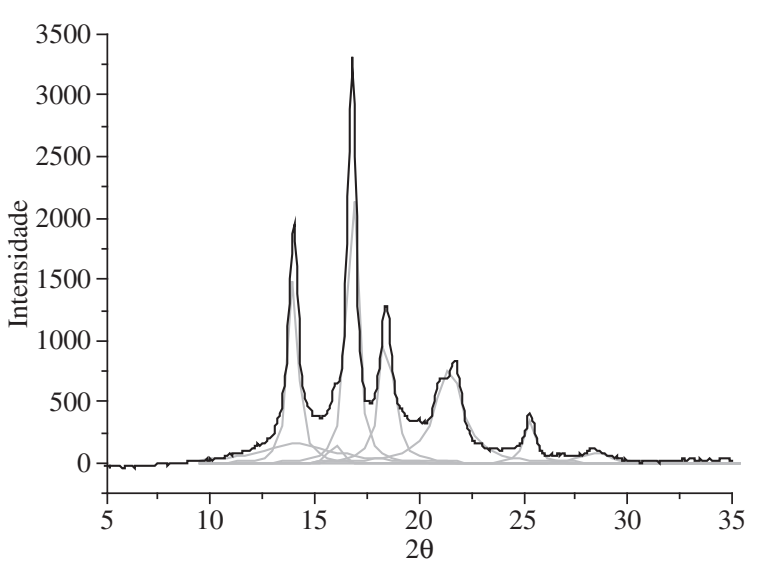

(b)

Figura 6. Difratograma da superfície de amostra de PP injetada no molde de aço com fluido de resfriamento a) $15^{\circ} \mathrm{C}$; e b) $75^{\circ} \mathrm{C}$.

Os valores de tensão de escoamento e módulo de elasticidade dos corpos-de-prova em PP injetados nos moldes em compósito epóxi/alumínio e em aço são mostrados na Tabela 3. Com o aumento da temperatura do fluido de resfriamento de 15 para $75{ }^{\circ} \mathrm{C}$, os valores de tensão de escoamento e de módulo de elasticidade dos corpos-de-prova em PP injetados nos moldes em compósito epóxi/alumínio apresentaram um leve incremento de 32 e $1825 \mathrm{MPa}$, para valores próximos a 34 e $1830 \mathrm{MPa}$, respectivamente. Um comportamento sob tração similar foi observado para os corpos-de-prova injetados em molde de aço como mostra a Tabela 3. Contudo, ressalta-se que os referidos incrementos não são significativos pois encontram-se dentro dos valores de desvio padrão.

Difratogramas de raio $\mathrm{X}$ obtidos da superfície dos corposde-prova de PP injetados nos moldes de epóxi/alumínio e de aço são mostrados nas Figuras 5 e 6 . A deconvolução (desmembramento dos picos) dos difratogramas de raio $\mathrm{X}$ realizados em amostras dos corpos-de-prova mostrou a presença de fase amorfa e de duas fases cristalinas do PP, $\alpha$ e $\beta$ (sis-
Tabela 4. Ângulos de difração das fases cristalinas $\alpha$ e $\beta$ do PP.

\begin{tabular}{ccc}
\hline Plano cristalino & Ângulo 2 $\theta$ & Fase cristalina \\
\hline$[300]$ & $16,1^{\circ}$ & $\beta$ \\
{$[110]$} & $14,1^{\circ}$ & $\alpha$ \\
{$[040]$} & $16,8^{\circ}$ & $\alpha$ \\
{$[130]$} & $18,8^{\circ}$ & $\alpha$ \\
\hline
\end{tabular}

Tabela 5. Grau de cristalinidade e percentagem das fases cristalinas na superfície das amostras injetadas no molde em composito epóxi/alumínio e em molde em aço usando fluido de resfriamento a temperaturas diferentes.

\begin{tabular}{ccccc}
\hline \multirow{2}{*}{$\begin{array}{c}\text { Temperatura do fluido } \\
\text { de resfriamento }\left({ }^{\circ} \mathbf{C}\right)\end{array}$} & \multicolumn{5}{c}{ PP em molde epóxi/Al } \\
\cline { 2 - 5 } & $\mathbf{K}$ & $\mathbf{X}_{\mathbf{c}}$ & $\% \beta$ & $\% \alpha$ \\
\hline 15 & 0,036 & 85,1 & 3,1 & 82,0 \\
32 & 0,037 & 87,3 & 3,2 & 84,1 \\
75 & 0,056 & 87,6 & 4,9 & 82,7 \\
\hline Temperatura do fluido & \multicolumn{4}{c}{$\mathbf{P P}$ em molde aço } \\
\cline { 2 - 5 } de resfriamento $\left({ }^{\circ} \mathbf{C}\right)$ & $\mathbf{K}$ & $\mathbf{X}_{\mathbf{c}}$ & $\mathbf{\%} \beta$ & $\% \alpha$ \\
\hline 15 & 0,026 & 66,9 & 1,8 & 65,1 \\
32 & 0,027 & 70,5 & 1,9 & 68,6 \\
75 & 0,028 & 82,5 & 2,3 & 80,2 \\
\hline
\end{tabular}

tema monoclínico e hexagonal, respectivamente). A Tabela 4 apresenta os principais ângulos de difração das fases cristalinas $\alpha$ e $\beta$ do PP

Os resultados do grau de cristalinidade e a percentagem de fases $\alpha$ e $\beta$ para as superfícies analisadas das peças em PP injetadas em moldes em compósito epóxi/alumínio e aço são apresentados na Tabela 5.

As amostras em PP injetadas no molde em compósito epóxi/alumínio apresentaram uma cristalinidade de 85,1 a $87,6 \%$, sendo que a maior cristalinidade foi encontrada nas peças injetadas nos moldes com fluido de resfriamento a $75{ }^{\circ} \mathrm{C}$, como esperado, uma vez que um molde com maior temperatura proporciona menores taxas de resfriamento facilitando o aumento do grau de cristalinidade. Foi ainda observado um leve incremento da fase $\beta$, com o aumento da temperatura do fluido de resfriamento. É bem conhecido que taxas lentas de resfriamento facilitam a formação de fase $\beta^{[15-17]}$.

O grau de cristalinidade das peças injetadas em PP injetadas em moldes de aço AISI 1045 foi de 66,9 a 82,5\%, valores menores que os encontrados para as peças injetadas em moldes em compósito epóxi/alumínio. O maior valor encontrado do grau de cristalinidade para as amostras injetadas foi para a temperatura do fluido de resfriamento de 75 ${ }^{\circ} \mathrm{C}$, o que poderia justificar os maiores valores encontrados para a tensão de escoamento destes corpos-de-prova. Nova- 
mente, a fase $\beta$ foi detectada em maior percentagem para as amostras injetadas com o fluido de resfriamento do molde a $75^{\circ} \mathrm{C}$. Os resultados obtidos indicam que a difusividade do compósito epóxi/alumínio é bastante baixa resultando em taxas de resfriamento capazes de influenciar a cristalinidade do PP, um polímero de cristalização rápida ${ }^{[18,19]}$, favorecendo um aumento da cristalinidade comparado a injeção em molde de aço com fluido de resfriamento na mesma temperatura.

\section{Conclusões}

A técnica de vazamento de resinas epóxi com partículas de alumínio mostrou-se uma alternativa bastante prática e eficaz para a fabricação rápida de moldes. Os ciclos de injeção de PP no molde de epóxi/alumínio foram mais longos, como esperado, aproximadamente de 200 segundos.

Os valores de dureza dos corpos-de-prova injetados no molde de aço e em molde epóxi/alumínio com fluido de refrigeração na mesma temperatura foram bastante próximos. O aumento da temperatura do fluido de resfriamento de 15 para $75{ }^{\circ} \mathrm{C}$, os valores de tensão de escoamento e de módulo de elasticidade dos corpos-de-prova em PP injetados nos moldes em compósito epóxi/alumínio apresentaram um leve incremento de 32 e $1825 \mathrm{MPa}$, para valores próximos a 34 e $1830 \mathrm{MPa}$, respectivamente. Um comportamento sob tração similar foi observado para os corposde-prova injetados em molde de aço.

As amostras em PP injetadas no molde em compósito epóxi/alumínio apresentaram uma cristalinidade de 85,1 a $87,6 \%$, A maior cristalinidade foi encontrada nas peças injetadas nos moldes com fluido de resfriamento a $75{ }^{\circ} \mathrm{C}$, como esperado, uma vez que um molde com maior temperatura proporciona menores taxas de resfriamento facilitando o aumento do grau de cristalinidade. Foi ainda observado um leve incremento da fase $\beta$, com o aumento da temperatura do fluido de resfriamento.

Os resultados obtidos indicam que o molde compósito epóxi/alumínio propicia baixas taxas de resfriamento capazes de influenciar a cristalinidade do PP, um polímero de cristalização rápida, favorecendo um aumento da cristalinidade comparado a injeção em molde de aço com fluido de resfriamento na mesma condição de fluxo e temperatura. Esse estudo mostrou que, de maneira geral, o molde compósito epóxi/alumínio tem um bom desempenho na moldagem por injeção de polipropileno tornando viável sua aplicação na produção de pequenas séries de protótipos ou de produtos de PP, onde os requisitos de projeto apresentem tolerâncias superiores a $20 \%$ com relação a variação de cristalinidade e $10 \%$ com relação a variação de propriedades mecânicas.

\section{Referências Bibliográficas}

1. Jacobs, P. F. - Stereolithography \& Other RP\&M Technologies: From Rapid To Rapid Tooling, 1st ed. Booknews Inc. (1996).

2. Alvarez, R. - "Time to market \& rapid tooling and OEM perspective". in: Annals of $57^{\text {th }}$ ANTEC Annual Technical Conference, New York (1999).

3. Dusel, K. H.; Eschl, J.; Eyerer, P. \& Luck, T. - "Simulation and Applications of the Injection Moulding Process". Institute for Polymer Testing and Polymer Science IKP - University of Stuttgart, Germany (1998).

4. Karapatis, N. P.; Van Griethuysen, J. P. S. \& Glardon, R. - "Direct rapid tooling: a review of current research". Rapid Prototyping Journal, MCB University Press, 4, p.77-89 (1998).

5. Radstok, E. - "Rapid Tooling". Rapid Prototyping Journal. MCB University Press, 5 (4) p.164-168 (1999).

6. Ferreira, J. C. \& Mateus, A. - "Studies of rapid soft tooling with conformal cooling channels for plastic injection moulding". Journal of Materials Processing Technology, 142, p.508-516 (2003).

7. Dunne, P.; Soe, S. P.; Byrne, G.; Venus, A; \& Wheatley, A. R. - "Some demands on rapid prototypes used as master patterns in rapid tooling for injection moulding“. Journal of Materials Processing Technology (2004).

8. Masood, S. H.; Song, W. Q.; Hodgkin, J. K. \& Friedl, C. - "Rapid Tooling for Injection Moulding using Fused Deposition Modelling". in: Annals of 57 $7^{\text {th }}$ ANTEC Annual Technical Conference, New York (1999).

9. Foggiatto, J. A.; Salmoria, G. V. \& Ahrens, C. - "Behavior of injection mold manufactured in ABS, PC and PPSF by Fused deposition modeling". Polymer Processing Society, Americas Regional Meeting Symposia, PPS 2004, Florianópolis-SC, Brazil (2004).

10. Chung, S. I.; Im, Y. G.; Jeong, H. D. \& Nakagawa, T. - "The effects of metal filler on the characteristics of casting resin for semi-metallic soft tools". Journal of Materials Processing Technology, 134, p.26-34 (2003).

11. Rees, H. - Mold Engineering, Carl Hanser Verlag, Munich (1995).

12. Li, Y.; Gargiulo, E. P. \& Keefe, M. - "Studies in direct rapid tooling using stereolithography“. Journal of Manufacturing Science and Engineering. 122, p.317-322 (2000).

13. Brito, Z. \& Sanchez, G. - "Influence of metallic fillers on the thermal and mechanical behaviour in composites of epoxy matrix". Composites Strutures, 48, p.79-81 (2000). 
14. Hunstman. Aluminium filled epoxy resin RenCast 436. Data sheet. Disponível em http://www.maxepoxi.com. br/sistemas_epoxi.asp.

15. Chen, H. B.; Karger-Kocsis, J.; Wu, J. S.; \& Varga, J. - "Fracture Toughness of alpha and Beta-phase polypropylene homopolymers and random and block copolymers“. Polymer, 43, p.6505-6514 (2002).

16. Grein, C; Plummer, C. J. G.; Kaush, H. H.; Germain, Y. \& Beguelin, P. H. - "Influence of Beta nucleation on the mechanical properties of isotactic polypropylene and rubber modified isotactic polypropylene". Polymer, 43, p.3279-3293 (2002).

17. Cermak, R.; Obadal, M.; Ponizil, P.; Polaskova, M.; Stoklasa, K. \& Lengalova, A. - "Injection moulded $\alpha$ and $\beta$-polypropylenes: I. Structure vs. Processing parameters". European Polymer Journal. 41, p.1838-1845 (2005)

18. Brucato, A. V.; Piccarolo, S. \& La Carrubba, V. - "An experimental methodology to study polymer crystallization under processing conditions. The influence of high cooling rates". Journal Chemical Engineering Science. 57, p.4129-4143 (2002).

19. Coccorullo, I.; Pantani, R. \& Titomanlio, G. - "Crystallization kinetics and solidified structure in iPP under high cooling rates". Polymer. 44, p.307-318 (2002).

Enviado: 16/09/07 Reenviado: 05/04/08

Aceito: $12 / 05 / 08$ 